\title{
Conditions for using digital isolators in intrinsically safe applications
}

\begin{abstract}
This article highlights the issues related to the use of the galvanic separation of digital circuits by employing modern digital isolators in intrinsically safe applications. The authors refer to the requirements of suitable standards and directives and present their interpretation. They also identified limitations related to the use of digital isolators in intrinsically safe circuits.
\end{abstract}

Key words: galvanic separation, digital isolators, intrinsically safe applications

\section{INTRODUCTION}

Among the components for performing the galvanic separation of digital transmission signals, a new group was launched into the market quite recently (after the year 2000); i.e., components functioning on the basis of capacitive or inductive coupling. Here, an important innovation was integrating the input/output interfaces of typical logical level CMOS together with circuits cooperating with coupling element, and the coupling element itself, in one component package. The crucial advantages of these components are their small size and high operating speed at a relatively low demand for energy (as compared with other galvanic separation methods). Two companies are precursors and leaders in the development of such components: Analog Devices, offering separators in the $i$ Coupler $₫$ technology [1] that makes use of inductive coupling; and Texas Instruments - offering separators in the ISO technology [2] that makes use of capacitive coupling. The use of separating components in intrinsically safe applications is conditioned by certain requirements contained in relevant standards. The application of measures allowing us to fulfill these requirements in the case of the described components implies their work in atypical conditions.
This results in a partial degradation of their functionality (particularly their maximal work speed), depending on the degree of deviation from nominal conditions [3].

\section{REQUIREMENTS OF STANDARDS AND DIRECTIVES}

The requirements of the following legal acts have to be fulfilled in the case of the solutions of intrinsically safe separators which separate fast intrinsically safe interfaces and operate in areas with explosion hazards:

Directive 2014/34/EU of the European Parliament and of the Council of 26 February 2014 on the harmonization of the laws of the Member States relating to equipment and protective systems intended for use in potentially explosive atmospheres, valid since 20 April 2016.

Standards of explosion-proof design:

1. PN-EN 60079-0:2013-03 + A11:2014-03 Explosive atmospheres - Part 0: Equipment - General requirements [4].

2. PN-EN 60079-11:2012 Explosive atmospheres Part 11: Equipment protection by intrinsic safety , $i$ " [5].

3. PN-EN 60079-25:2011 + AC:2014-08 Explosive atmospheres - Part 25: Intrinsically safe electrical systems [6]. 
The basis to use digital isolators in intrinsically safe circuits is Clause 8.9 Galvanically separating components of the standard PN-EN 60079-11:2012:

\subsubsection{General}

"An infallible isolating component conforming to the following shall be considered as not being capable of failing to a short-circuit across the infallible separation."

and

Clause 8.9.3 Isolating components between separate intrinsically safe circuits

"Isolating components shall be considered to provide infallible separation of separate intrinsically safe circuits if the following conditions are satisfied:

a) the rating of the device shall be according to 7.1 (with the exceptions given in that clause still being applicable) unless it can be shown that the circuits connected to these terminals cannot invalidate the infallible separation of the device. Protective techniques (such as those indicated in 8.9.2) may be necessary to avoid exceeding the rating of the isolating component;

b) the device shall comply with the dielectric strength requirements in accordance with 6.3.13. The manufacturer's insulation test voltage for the infallible separation of the component under test shall be not less than the test voltage required by 6.3.13."

An important reference of Clause 8.9.3 is Clause 6.3 .13 of the same standard: Dielectric strength requirement:

"The insulation between an intrinsically safe circuit and the frame of the electrical equipment or parts which may be earthed shall be capable of complying with the test described in 10.3 at an r.m.s. a.c. test voltage of twice the voltage of the intrinsically safe circuit or $500 \mathrm{~V}$ r.m.s. whichever is the greater. When the circuit does not satisfy this requirement, the apparatus shall be marked with the symbol " $X$ " and the documentation shall indicate the necessary information regarding the correct installation. (...)

Where breakdown between separate intrinsically safe circuits could produce an unsafe condition, the insulation between these circuits shall be capable of withstanding an r.m.s. test voltage of $2 U$, with a minimum of $500 \mathrm{~V}$ r.m.s., where $U$ is the sum of the r.m.s. values of the voltages of the circuits under consideration."

Isolators in the $i$ Coupler ${ }^{\circledR}$ and ISO technologies have a high dielectric strength whose values are included in the catalog cards of the isolator's basic versions and are presented in Table 1. The isolators manufactured according to these technologies have a test voltage not less than in the basic versions and fulfill the abovementioned requirements.

Table 1

Dielectric strength of isolators $[7,8]$

\begin{tabular}{|c|c|c|}
\hline $\begin{array}{l}\text { Manufacturer/ } \\
\text { Technology }\end{array}$ & $\begin{array}{c}\text { Analog Devices/ } \\
i \text { Coupler }{ }^{\circledR}\end{array}$ & $\begin{array}{l}\text { Texas Instruments/ } \\
\text { ISO }\end{array}$ \\
\hline System & ADuM 1100 & ISO 721 \\
\hline $\begin{array}{l}\text { Safety } \\
\text { and } \\
\text { confirmation } \\
\text { of compliance }\end{array}$ & $\begin{array}{c}\text { VIORM = } \\
=560 \mathrm{~V} \text { peak } \\
2500 \mathrm{~V} \mathrm{rms} \\
\text { for } 1 \text { minute } \\
\text { no breakdowns } \\
\text { acc. to UL } 1577 \\
\text { Basic insulation } \\
4000 \mathrm{~V} \text { peak }\end{array}$ & $\begin{array}{c}\text { VIORM = } \\
=560 \mathrm{~V} \mathrm{peak} \\
2500 \mathrm{~V} \mathrm{rms} \\
\text { for } 1 \text { minute } \\
\text { no breakdowns } \\
\text { acc. to UL } 1577 \\
\text { Basic insulation } \\
4000 \mathrm{~V} \text { peak }\end{array}$ \\
\hline
\end{tabular}

It is important to note that, contrary to Clause 8.9.3 (which refers to components isolating different intrinsically safe circuits in Clause 8.9.2), Isolating components between intrinsically safe and non-intrinsically safe circuits, states:

"Isolating components shall comply with the following:

a) The requirements of Table 5 shall also apply to the isolating element except that for inside sealed devices; e.g., opto-couplers, Column 5, 6, and 7 shall not apply. If Table F.1 is applied, Column 2 shall not apply."

Based on the above requirements in the standards, it is possible to use digital isolators for galvanic separation between intrinsically safe circuits.

The validity of the above interpretation of requirements is confirmed by the staff of ATEX-notified entities who positively evaluated documentations of devices applying digital isolators.

\section{LIMITATIONS OF ISOLATOR PARAMETERS}

The datasheets of digital isolators $i$ Coupler ${ }^{\circledR}$ by Analog Devices and ISO by Texas Instruments contain limitations as far as the particular component operations are concerned that condition their proper application:

1) power dissipated in the package,

2) or supply current of the primary and secondary sides,

3) and current in the transmission line of the isolator of the primary and secondary sides,

4) supply voltage, input voltage, output voltage. 


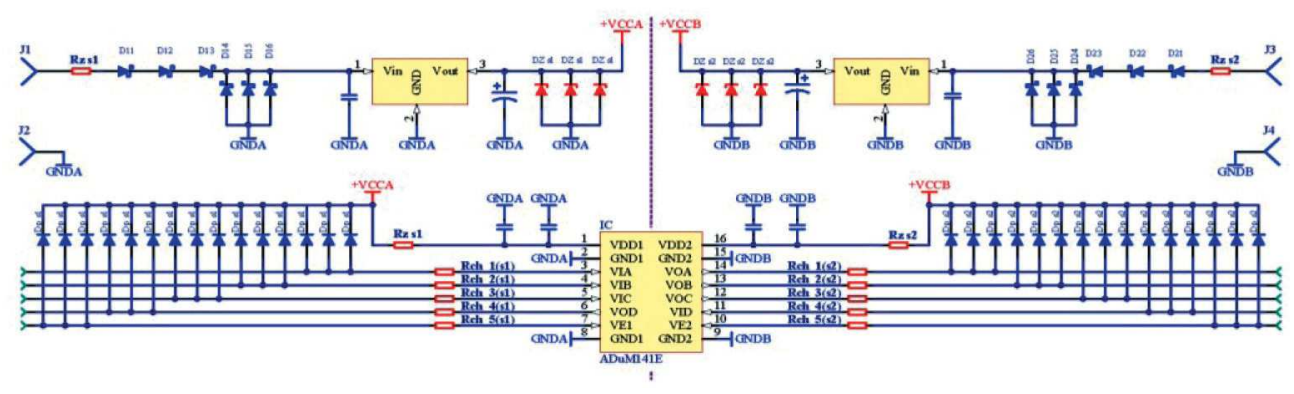

Fig. 1. Diagram of circuit of four-channel isolator ADuM141 in intrinsically safe application

Figure 1 features a sample system that fulfills the above limitations for the intrinsically safe application for Analog Devices separators (analogical interpretation can be presented for Texas Instruments separators).

In the circuit, there are two alternative ways to limit the dissipated power (supply current) depending on the place of their application by using resistors Rz s1 (Rz s2). The maximal total power dissipated in isolator $P_{\max } I C\left(T_{a}\right)$ with respect to ambient temperature is:

$$
P_{\max } I C\left(T_{a}\right)=P_{\max } s 1\left(T_{a}\right)+P_{\max } s 2\left(T_{a}\right)
$$

where:

$P_{\max } x 1\left(T_{a}\right)$ - power supplied to the isolator from the primary side,

$P_{\max } s 2\left(T_{a}\right)-$ power supplied to the isolator from the secondary side.

On the primary side, the power supplied to the circuit is:

$$
P_{\max } s 1\left(T_{a}\right)=\frac{U z^{2}[D Z(s 1)]_{\max }}{4 \cdot R z(s 1)_{\min }}+\sum_{i=n}^{i=1} \frac{U i_{\max }^{2}(s 1)}{4 \cdot R c h \_n(s 1)_{\min }}
$$

where:

$$
\begin{aligned}
& U z[D Z(s 1)]_{\max }- \text { maximal supply voltage of the pri- } \\
& \text { mary side, } \\
& R z(s 1)_{\min }- \text { minimal series resistance of the sup- } \\
& \text { ply of the primary side, } \\
& U i_{\max }(s 1)- \text { maximal input voltage on the } n \text {-th } \\
& \text { channel of the isolator of the } \\
& \text { primary side, } \\
& R c h \_n(s 1)_{\min }- \text { minimal series resistance of the } \\
& n \text {-th channel of the isolator. }
\end{aligned}
$$

Analogically, on the secondary side the power supplied to the circuit is:

$$
P_{\max } s 2\left(T_{a}\right)=\frac{U z^{2}[D Z(s 2)]_{\max }}{4 \cdot R z(s 2)_{\min }}+\sum_{i=n}^{i=1} \frac{U i_{\max }^{2}(s 2)}{4 \cdot R c h \_n(s 2)_{\min }}
$$

where:

$$
\begin{aligned}
U z[D Z(s 2)]_{\max }- & \text { maximal supply voltage of the } \\
& \text { secondary side, } \\
R z(s 2)_{\min }- & \text { minimal series resistance of } \\
& \text { the supply of the secondary side, } \\
U i_{\max }(s 2)- & \text { maximal input voltage on the } n \text {-th } \\
& \text { channel of the isolator of the se- } \\
& \text { condary side, } \\
R c h \_n(s 2)_{\min }- & \text { minimal series resistance of the } \\
& n \text {-th channel of the isolator of } \\
& \text { the secondary side. }
\end{aligned}
$$

\subsection{Limitation of maximal total power dissipated in the isolator package}

The maximal total power dissipated in isolator $P_{\max } I C\left(T_{a}\right)$ with respect to ambient temperature $\left(T_{a}\right)$ should not exceed (Fig. 2).

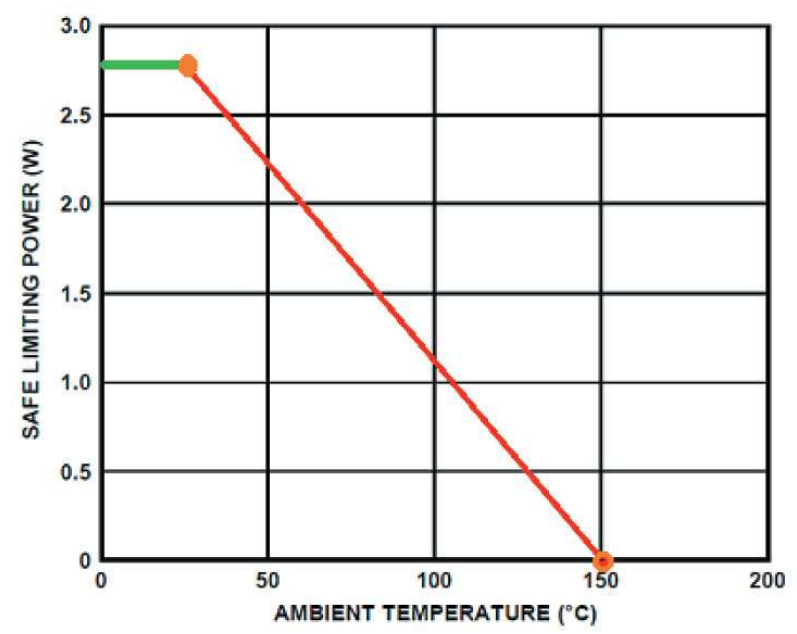

Fig. 2. Thermal Derating Curve for RW-16 Wide Body [SOIC_W] Package, Dependence of Safety Limiting Values with Ambient Temperature per DIN V VDE V 0884-10 based on example of four-channel isolator ADuM14x [9] 
For $T_{a} \leq 25^{\circ} \mathrm{C}$

$$
P_{\max } I C\left(T_{a}\right)=P_{T P D \_\max }
$$

For $25^{\circ} \mathrm{C}<T_{a} \leq 150^{\circ} \mathrm{C}$ from a linear equation based on the characteristic two points for this case $\left(150^{\circ} \mathrm{C}\right.$, $\left.0 \mathrm{~W} ; 25^{\circ} \mathrm{C}, 2.78 \mathrm{~W}\right)$.

$$
P_{\max } I C\left(T_{a}\right)=\frac{\left(P_{T P D_{-} T j \max }-P_{T P D_{-} \max }\right) \cdot\left(T a-T j_{T P D_{-} \max }\right)+P_{T P D_{-} \max } \cdot\left(T j_{\max }-T j_{T P D_{-} \max }\right)}{T j_{\max }-T_{T P D_{-} \max }}
$$

where:

$$
\begin{aligned}
P_{T P D_{-} T j \max }- & \begin{array}{l}
\text { maximal power that can be dissipated } \\
\text { at maximal temperature of the junction }
\end{array} \\
& \text { (typically, } 0 \mathrm{~mW}), \\
P_{T P D_{-} \text {max }-} & \text { maximal power that can be dissipated } \\
& \text { at room temperature (typically, } \left.25^{\circ} \mathrm{C}\right), \\
T a- & \text { assumed work temperature, } \\
T j_{T P D_{-} \max -} & \text { maximal temperature of the junction } \\
& \text { at which the maximal power can be } \\
& \text { dissipated (typically, } \left.25^{\circ} \mathrm{C}\right), \\
T j_{\max }- & \text { maximal temperature of the junction } \\
& \left(\text { typically, } 150^{\circ} \mathrm{C}\right) .
\end{aligned}
$$

\subsection{Limitation of maximal supply current of the primary and secondary side}

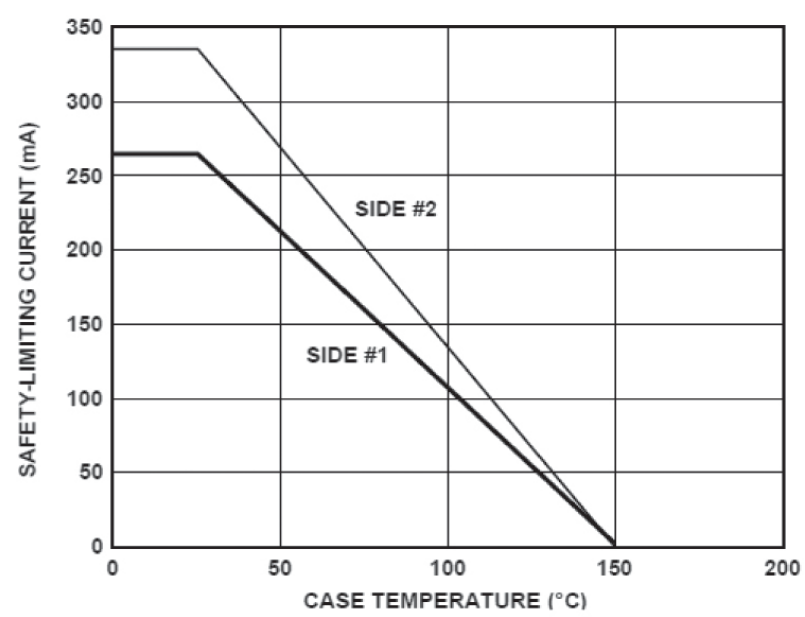

Fig. 3. Thermal Derating Curve, Dependence of Safety-Limiting Values with Case Temperature per DIN VVDE $V$ 0884-10 based on example of three-channel isolator ADuM130x [10]

Analogically to item 3.1, the value of the supply current of each side is determined from a linear equation based on two characteristic points with respect to ambient temperature. This value is a safe boundary value.
The critical value of the package temperature is the temperature of the junction.

\subsection{Limitation of maximal current in the isolator transmission line of the primary and secondary side}

The value of the limited maximal current in the isolator transmission line of the proper side $\left(I_{o 1}, I_{o 2}\right)$ should be referred to the dependence of safety boundary values on temperature.

\begin{tabular}{|l|l|}
\hline Parametr & Rating \\
\hline Storage Temperature $\left(T_{S T}\right)$ & $-65^{\circ} \mathrm{C}$ to $+150^{\circ} \mathrm{C}$ \\
Ambient Operating Temperature $\left(T_{A}\right)^{1}$ & $-40^{\circ} \mathrm{C}$ to $+105^{\circ} \mathrm{C}$ \\
Ambient Operating Temperature $\left(T_{A}\right)^{2}$ & $-40^{\circ} \mathrm{C}$ to $+125^{\circ} \mathrm{C}$ \\
Supply Voltages $\left(V_{D D 1}, V_{D D 2}\right)^{3}$ & $-0.5 \mathrm{~V}$ to $+7.0 \mathrm{~V}$ \\
Output Voltage $\left(V_{O A}, V_{O B}, V_{O C}\right)^{3,4}$ & $-0.5 \mathrm{~V}$ to $V_{D D I}+0.5 \mathrm{~V}$ \\
Average Output Current per $\mathrm{Pin}^{5}$ & $-0.5 \mathrm{~V}$ to $V_{D D O}+0.5 \mathrm{~V}$ \\
$\quad$ Side $1\left(I_{O 1}\right)$ & $-23 \mathrm{~mA}$ to $+23 \mathrm{~mA}$ \\
Side 2 $\left(I_{O 2}\right)$ & $-30 \mathrm{~mA}$ to $+30 \mathrm{~mA}$ \\
Common-Mode Transients & \\
\hline
\end{tabular}

Fig. 4. Sample definitions of safety boundary values $\left(I_{o 1}, I_{O 2}\right)$; limitation of current in a transmission line to a safe value based on example of three-channel isolator ADuM130x [10]

The maximal current in the transmission channel of the primary side in isolator $I_{\max } c h \_s 1\left(T_{a}\right)$ with respect to ambient temperature $\left(T_{a}\right)$ should not exceed:

For $T_{a} \leq 25^{\circ} \mathrm{C}, I_{\max } c h \_s 1\left(T_{a}\right)=I_{o 1 \_} \max$ 
For $25^{\circ} \mathrm{C}<T_{a} \leq 150^{\circ} \mathrm{C}$ from a linear equation based on two points.

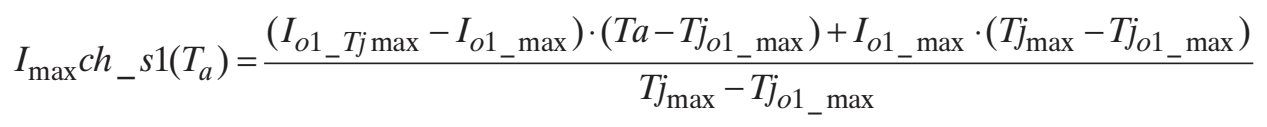

where:

$$
\begin{aligned}
I_{o 1_{-} T j \max -}- & \text { maximal current that can flow at maxi- } \\
& \text { mal temperature of the junction } \\
& \text { (typically, } 0 \mathrm{~mA}), \\
I_{o 1_{-} \max }- & \text { maximal current that can flow at room } \\
& \text { temperature (typically, } \left.25^{\circ} \mathrm{C}\right), \\
T a- & \text { assumed work temperature, } \\
T j_{o 1_{-} \max }- & \text { maximal temperature of the package } \\
& \text { at which the maximal current can flow } \\
& \text { (typically, } \left.25^{\circ} \mathrm{C}\right), \\
T j_{\max }- & \text { maximal temperature of the junction } \\
& \text { (typically, } \left.150^{\circ} \mathrm{C}\right) .
\end{aligned}
$$

Then, it is possible to determine the minimal series resistance on the $n$-th channel $R c h \_n(s 1)_{\min }$; for example, for the primary side $(s 1)$ :

$$
R c h \_n(s 1)_{\min }=\frac{U i_{\max }(s 1)}{I_{\max } c h \_s 1\left(T_{a}\right)}
$$

where:

$$
\begin{aligned}
U i_{\max }(s 1)- & \text { maximal input voltage on the } n \text {-th } \\
& \text { channel of the isolator of the } \\
& \text { primary side, } \\
I_{\max } c h_{-} s 1\left(T_{a}\right)- & \text { maximal current in the } n \text {-th chan- } \\
& \text { nel of the isolator. }
\end{aligned}
$$

Analogical dependencies are relevant for the secondary side of the isolator.

The necessity to use series resistances that limit the current and power in the transmission lines results in functional limitations. These resistances, together with the input capacitancies of the isolators and circuits co-operating with the isolators, create low-pass filters which distort the transmitted signals and limit the maximal speed values or have a negative impact on the time dependencies between the transmitted signals.

\subsection{Limiting power supply of the isolator sides, limiting input and output voltage}

The datasheets of digital isolators define the maximal supply voltage values and maximal voltage values on the transmission lines of each side. In intrinsically safe applications in circuits without input voltage limiters, it is necessary to formally limit the voltage to values below $6.0 \mathrm{~V}$ for circuits in the ISO technology and below $7.0 \mathrm{~V}$ for circuits in the $i$ Coupler ${ }^{\circledR}$ technology. In the case of the power supply in a typical intrinsically safe application, the applied security measures are parallel voltage limiters composed of $5 \%$ Zener diodes.

The maximal voltage results from the voltage of the Zener diode (with $5 \%$ tolerance) from the given type series of diodes, which ensures that the values defined in the datasheets are not exceeded. The maximal voltage for the $i$ Coupler ${ }^{\circledR}$ technology is $7.0 \mathrm{~V}$ in intrinsically safe application $U i=6.51 \mathrm{~V}, U o=6.51 \mathrm{~V}$.

The maximal supply voltage for the ISO technology is $6.0 \mathrm{~V}$ in intrinsically safe application $U i=5.88 \mathrm{~V}$, $U o=5.88 \mathrm{~V}$.

The datasheets of digital isolators define the maximal input and output voltage values of each side. These voltages cannot exceed the value established with respect to the supply voltage of the given side of the isolator.

Extra limitation of voltage on the isolator inputs/outputs is not required when only the circuit supplied by the same limiter as the isolator itself is connected to the inputs/outputs of the given side and when it is possible to prove that the input/output voltage will not be greater than the isolator supply voltage in any case. Otherwise, it will be necessary to ensure that the value of the input/ output voltage will not exceed the value defined in the datasheet. This can be done, for example, by using parallel voltage limiters in the form of infallible diodes connected between the input/output lines and the isolator supply in a way that would ensure the infallibility of these connections (Dp_s1 diodes of the primary side and Dp_s2 diodes of the secondary side in Fig. 1).

Experiences show that it is possible to use diode voltage limiters on input/output lines; however, with a significant limitation of maximal transmission speed as compared to catalog data (to $2 \mathrm{Mbps}$ in the case of circuits made in the $i$ Coupler ${ }^{\circledR}$ technology and to $3.675 \mathrm{Mbps}$ in the case of circuits made in the ISO technology). For solutions with diode voltage limiters on transmission lines, the admissible vales of voltage before the limiters will depend on the circuit topology, value of the elements, and parameters of diodes used in the limiters. 


\section{CONCLUSIONS}

In comparison to alternative solutions in the galvanic separation of digital signals, integrated isolators allow to perform the separation at a relatively low demand for energy with respect to the offered transmission speed and the number of separated channels. The use of such isolators in intrinsically safe applications to separate particular intrinsically safe circuits is possible, provided that standard requirements are fulfilled. However, the measures and circuit solutions applied for this purpose partly limit their functionality and separation parameters with respect to catalog definitions. In spite of these disadvantages, integrated isolators are used particularly for local separation of fast interfaces with a high number of transmission lines.

\section{References}

[1] Scott W.: iCoupler ${ }^{\circledR}$, Digital Isolators Protect RS-232, $R S-485$, and CAN Buses in Industrial, Instrumentation and Computer Applications, "Analog Dialogue" 39-10, October 2005, [online:]

http://www.analog.com/library/analogdialogue/archives/ 39-10/iCoupler.pdf [access 18.11.2015].

[2] Kugelstadt T.: Industrial data-acquisition interfaces with digital isolators, "Analog Applications Journal" 3Q 2011 [online:] http://www.ti.com/lit/an/slyt426/slyt426.pdf [access 18.11.2015]

[3] Chmielarz S., Molenda T.: Modern technologies of galvanic separation of digital signals and their possible applications in intrinsically safe devices, "Mining - Informatics, Automation and Electrical Engineering" 2015, 3: 59-67.
[4] PN-EN 60079-0:2013-03 + A11:2014-03: Atmosfery wybuchowe - Czesśc 0: Urzadzenia - Podstawowe wymagania. [5] PN-EN 60079-11:2012: Atmosfery wybuchowe - Część 11: Zabezpieczenie urzadzeń za pomoca iskrobezpieczeństwa " $i$ ".

[6] PN-EN 60079-25:2011 + AC:2014-08: Atmosfery wybuchowe - Część 25: Systemy iskrobezpieczne.

[7] Analog Devices Inc.: Data Sheet iCoupler Digital Isolator ADuM1100: rev. K 2015, [online:] http://www.analog.com/ media/en/technical-documentation/data-sheets/ADUM1100.pdf [access 18.11.2015].

[8] Texas Instruments: Data Sheet ISO72x Single Channel High-Speed Digital Isolators ISO721, ISO721M, ISO722, ISO722M SLLS629L - January 2006 - Revised October 2015, [online:] http://www.ti.com/lit/ds/symlink/iso722.pdf [access 18.11.2015].

[9] Analog Devices Inc.: Data Sheet 3.0 kV RMS / 3.75 kV RMS Quad Digital Isolators ADuM140D/ADuM140E ADuM141D/ ADuM141E/ADuM142D/ADuM142E rev. M 2016, [online:] http://www.analog.com/media/en/technical-documentation/ data-sheets/ADuM140D_140E_141D_141E_142D_142E.pdf [access 29.08.2016].

[10] Analog Devices Inc.: Data Sheet Triple-Channel Digital Isolators ADuM1300/ADuM1301 rev. K 2015, [online:] http://www.analog.com/media/en/technical-documentation/ data-sheets/ADuM1300_1301.pdf [access 18.11.2015].

SŁAWOMIR CHMIELARZ, Ph.D., Eng. TOMASZ MOLENDA, Ph.D., Eng. PIOTR SZYMAEA, Ph.D., Eng.

WOJCIECH KORSKI, Ph.D., Eng. Institute of Innovative Technologies EMAG ul. Leopolda 31, 40-189 Katowice, Poland \{S.Chmielarz, T.Molenda, P.Szymala, W.Korski\}@ibemag.pl 